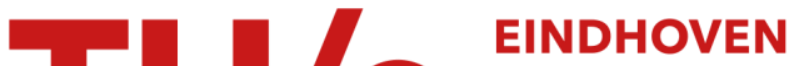 UNIVERSITY OF TECHNOLOGY
}

\section{Ultra-sharp and highly tolerant waveguide bends for InP photonic membrane circuits}

\section{Citation for published version (APA):}

Jiao, Y., Liu, J., Millan Mejia, A. J., Shen, L., \& van der Tol, J. J. G. M. (2016). Ultra-sharp and highly tolerant waveguide bends for InP photonic membrane circuits. IEEE Photonics Technology Letters, 28(15), 1637-1640. https://doi.org/10.1109/LPT.2016.2565607

DOI:

10.1109/LPT.2016.2565607

Document status and date:

Published: 10/05/2016

\section{Document Version:}

Publisher's PDF, also known as Version of Record (includes final page, issue and volume numbers)

\section{Please check the document version of this publication:}

- A submitted manuscript is the version of the article upon submission and before peer-review. There can be important differences between the submitted version and the official published version of record. People interested in the research are advised to contact the author for the final version of the publication, or visit the $\mathrm{DOI}$ to the publisher's website.

- The final author version and the galley proof are versions of the publication after peer review.

- The final published version features the final layout of the paper including the volume, issue and page numbers.

Link to publication

\section{General rights}

Copyright and moral rights for the publications made accessible in the public portal are retained by the authors and/or other copyright owners and it is a condition of accessing publications that users recognise and abide by the legal requirements associated with these rights.

- Users may download and print one copy of any publication from the public portal for the purpose of private study or research.

- You may not further distribute the material or use it for any profit-making activity or commercial gain

- You may freely distribute the URL identifying the publication in the public portal.

If the publication is distributed under the terms of Article 25fa of the Dutch Copyright Act, indicated by the "Taverne" license above, please follow below link for the End User Agreement:

www.tue.nl/taverne

Take down policy

If you believe that this document breaches copyright please contact us at:

openaccess@tue.nl

providing details and we will investigate your claim. 


\title{
Ultra-Sharp and Highly Tolerant Waveguide Bends for InP Photonic Membrane Circuits
}

\author{
Yuqing Jiao, Member, IEEE, Jian Liu, Alonso Millan Mejia, Longfei Shen, and \\ Jos van der Tol, Member, IEEE
}

\begin{abstract}
In this letter, we present a sharp bend design for the InP-based photonic membrane, which shows low loss and high tolerance. The traditional arc bends on InP membranes face high loss when the bending radii reduce below $2 \mu \mathrm{m}$. In addition, their performance deteriorates even more dramatically at the presence of waveguide footings. The proposed design has the advantages of low loss, high compactness, wide spectral response, and ease of fabrication. It is also verified to be much more resilient to design and fabrication variations, such as waveguide footings. The sharp bend is fabricated together with traditional arc bends. Experimental results confirm its potential as a basic building block for InP photonic membrane platforms.
\end{abstract}

Index Terms - Waveguides, bends, photonic integrated circuit.

\section{INTRODUCTION}

$\mathbf{P}$ HOTONIC membrane technologies [1]-[3] are intensively studied over the past decade as promising candidates for the next-generation photonic integrated circuits (PICs). One of the most important advantages of membrane technology is the compact device size. The optical confinement in membrane waveguides can be greatly enhanced by using an optical buffer layer between the membrane and the substrate. The optical buffer layer can be $\mathrm{SiO}_{2}$ for silicon-based membrane platforms [3] or polymer/ $\mathrm{SiO}_{2}$ for indium phosphide ( $\mathrm{InP}$ ) based membrane platforms [1], [2]. As a result, the waveguide dimensions are reduced down to the sub-micron range.

Waveguide bends are critical components in realizing complex photonic circuits [4]. The bends have to be both compact and low-loss for maximized circuit integration density and performance. This is especially important in applications such as on-chip optical interconnects [5], with very strict space and power consumption limits. On silicon membranes, waveguide bending radius as small as $1 \mu \mathrm{m}$ has been demonstrated [6] with $90^{\circ}$ bending loss of $0.09 \mathrm{~dB}$. The loss can be further reduced with special spline designs [7].

The situation on InP membranes is quite different. The waveguide bends in InP membrane circuits have not been systematically studied yet. The important fact is that the refractive

Manuscript received February 11, 2016; revised March 24, 2016; accepted May 5, 2016. Date of publication May 10, 2016; date of current version May 23, 2016. This work was supported by the European Research Council through the Project Advanced Grant NOLIMITS.

The authors are with the COBRA Research Institute, Eindhoven University of Technology, Eindhoven 5600 MB, The Netherlands (e-mail: y.jiao@tue.nl; j.liu@student.tue.nl; a.millan.mejia@tue.nl; 1.shen@tue.nl; j.j.g.m.v.d.tol@ tue.nl).

Color versions of one or more of the figures in this letter are available online at http://ieeexplore.ieee.org.

Digital Object Identifier 10.1109/LPT.2016.2565607
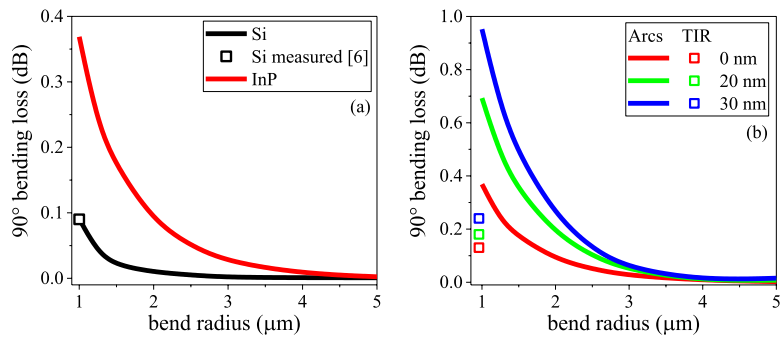

Fig. 1. (a) Simulated $90^{\circ}$ bending loss in silicon and InP membrane waveguides. The waveguide dimensions are $450 \times 220 \mathrm{~nm}$ and $400 \times 300 \mathrm{~nm}$ respectively. The black square is the reported value for a silicon waveguide [6], matching well with the simulation. (b) Simulated $90^{\circ}$ bending loss in InP membrane waveguides with different footing values. Red, green and blue squares represent the loss of the proposed sharp bend at corresponding footings.

index of $\operatorname{InP}(n=3.16)$ is lower than that of silicon $(n=3.47)$. Therefore there is a lower index contrast for the InP membrane waveguides. This can lead to higher radiative loss in the bends, and stronger scattering from sidewalls. Therefore a larger minimum bending radius as compared to the silicon membrane counterparts is required. Figure 1(a) depicts the calculated $90^{\circ}$ bending loss for both silicon and InP sub-micron waveguides, using a rigorous 3D finite difference time domain (FDTD) algorithm. As can be seen the InP membrane waveguides experience higher bending loss than the silicon counterparts, which is attributed to the relatively reduced index contrast.

Moreover, in the InP membrane platform, a certain thickness of footing $(\sim 20 \mathrm{~nm})$ is sometimes incorporated, to protect important epitaxial layers and bonding interfaces beneath the waveguide layer during the processing. The existence of a footing has no influence on the mode propagation properties of straight waveguides. But it can be an extra source of loss in waveguide bends, as shown in Fig. 1(b). Significant increase of bending loss is observed in the presence of footing, and the loss is very sensitive to the thickness variation of the footing. Therefore a solution that can avoid both problems presented in Fig. 1(a) and (b) is greatly desired.

In this letter we propose a novel waveguide bend design, using the principle of total internal reflection (TIR) to improve the performance as well as reduce the footprint. The design is much less sensitive to the footing as compared to traditional arc bends. The proposed design as well as traditional arc bends are fabricated and experimentally analyzed and compared. The results of the novel bend show an effective bending radius of only $0.96 \mu \mathrm{m}$ and a low bending loss over a wide wavelength band. 

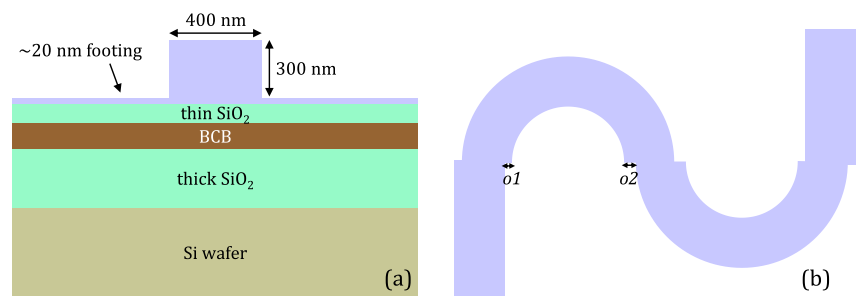

Fig. 2. (a) Cross-sectional view of the typical InP membrane passive waveguides. (b) Schematic diagram of traditional arc bends with optimized offsets for loss reduction.

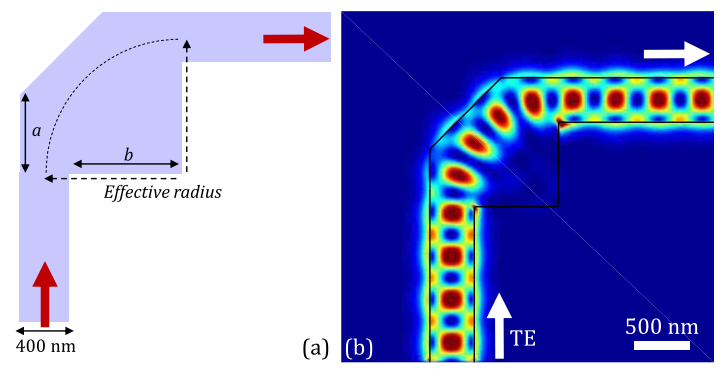

Fig. 3. (a) Schematic diagram of proposed sharp bend on InP membrane. (b) Calculated instantaneous electric field distribution for TE mode input in the optimized structure.

\section{DESIGN AND Simulation}

The cross-sectional view of the typical InP membrane passive waveguide is shown in Fig. 2(a). The InP membrane is bonded to the silicon wafer with $\mathrm{BCB}$ polymer. The processing of the membrane devices is based on electron-beam lithography (EBL) and dry etching. The resulting waveguide dimensions of $400 \mathrm{~nm}$ wide by $300 \mathrm{~nm}$ high ensure singlemode operation around the wavelength of $1550 \mathrm{~nm}$, while the $\sim 20 \mathrm{~nm}$ footing left in the etched region protects the epitaxial and bonding layers during the processing.

The schematic diagram of the traditional arc bends is shown in Fig. 2(b). Radiative loss is the major contribution to the total bending loss. In the bends, the optical mode will be pushed towards the outer edge of the waveguide, leaving a much stronger evanescent field outside the waveguide core. It increases dramatically as the bending radius decreases, as can be seen in Fig. 1(b). To minimize extra loss due to mode mismatch at the junctions between straight waveguide and arc bend, and between two arc bends with opposite curvatures, lateral offsets (shown as $o 1$ and $o 2$ in Fig. 2(b)) are introduced [8]. Sharper bends require much larger offsets since the mode mismatch is more severe. For a relatively large radius such as $10 \mu \mathrm{m}$, the offsets $o 1$ and $o 2$ are 4 and $8 \mathrm{~nm}$ respectively. When the radius reduces to $1.5 \mu \mathrm{m}$, the $o 1$ and $o 2$ can be as large as 30 and $60 \mathrm{~nm}$.

As motivated by the challenges discussed in the introduction, we present an ultra-sharp bend design using the TIR principle. A schematic diagram of such a sharp bend on InP membrane is shown in Fig. 3(a). This concept utilizes a $45^{\circ}$ facet for sharp turning of the light, and an extended square region for loss optimization. The concept was originally proposed by [9]. But it was based on 2D assumptions, and has not ever been verified in any real waveguide platforms. In this work, the structure is simulated and optimized with a
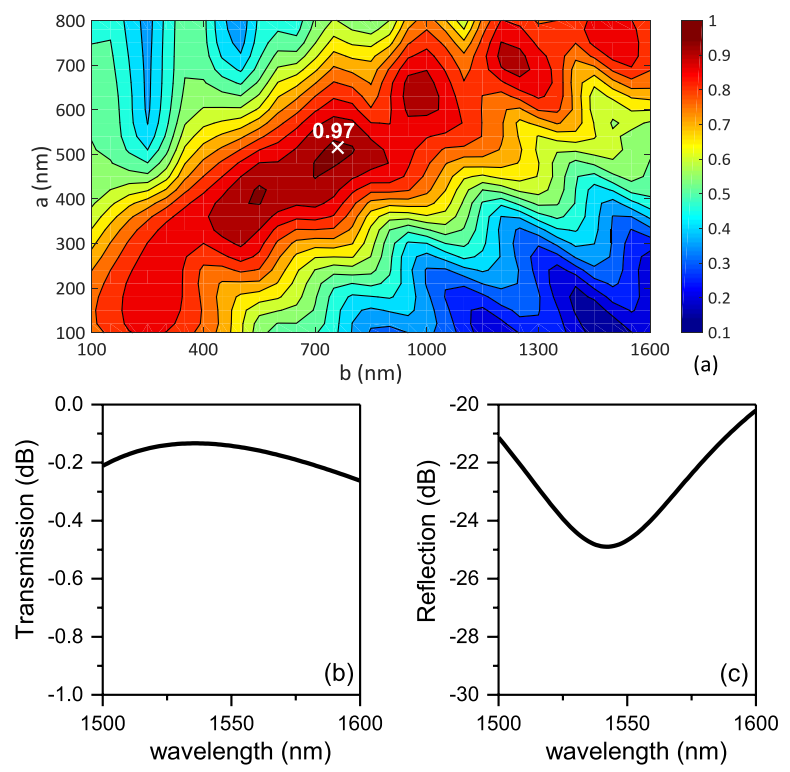

Fig. 4. (a) Optical transmission of the proposed structure calculated at $1550 \mathrm{~nm}$ wavelength as a function of the structure parameters $a$ and $b$. (b) Optical transmission as a function of wavelength. (c) Reflection as a function of wavelength.

3D finite difference time domain (FDTD) algorithm. An example of the calculated instantaneous electric field distribution in this structure, for transverse electric (TE) mode input, is shown in Fig. 3(b). As can be seen the TE mode is bent $90^{\circ}$ at the $45^{\circ}$ facet and is almost lossless.

To examine the geometric tolerance of this component, the optical transmission is calculated at $1550 \mathrm{~nm}$ wavelength as a function of the structure parameters $a$ and $b$, as shown in Fig. 4(a). The best optical transmission of 0.97 is marked in the figure as a white cross, corresponding to $a$ and $b$ values of $515 \mathrm{~nm}$ and $760 \mathrm{~nm}$ respectively. From the figure one can also see that when the $a$ and $b$ value deviate $\pm 100 \mathrm{~nm}$ from the optimum value, the optical transmission of the device only decreases from $0.97(-0.13 \mathrm{~dB})$ to about $0.9(-0.46 \mathrm{~dB})$. This indicates a very high fabrication tolerance of the device, which is very suitable for the large-scale membrane process.

The wavelength dependence of the transmission and reflection of the device is shown in Fig. 4(b) and (c). As can be seen, very low wavelength dependence is observed. The optical transmission spectrum over the entire $100 \mathrm{~nm}$ wavelength band has only $0.07 \mathrm{~dB}$ variation. The reflection back into the input waveguide is low (below $-20 \mathrm{~dB}$ ) over the $100 \mathrm{~nm}$ wavelength band.

Another advantage of this sharp bend structure is the elimination of mode mismatch existing in traditional arc bend connections. Therefore there will be no lateral offsets and no connection loss between different bends. The cascade of the sharp bend structures to form a $180^{\circ}$ bend is also studied. As can be seen in Fig. 3(b), the extended square region acts as a buffer to reduce the mode leakage in the bend. Therefore it contains minor optical power. When two such structures are connected to form a $180^{\circ}$ bend, it is necessary to avoid coupling between these minor optical fields in the square regions, as shown schematically in Fig. 5(a). The gap width $g$ is optimized to be $150 \mathrm{~nm}$ to avoid this coupling. This is 


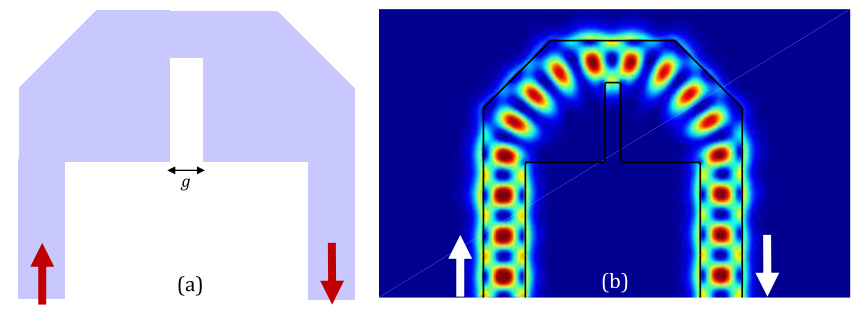

Fig. 5. (a) Schematic diagram of the cascaded $180^{\circ}$ bend. (b) Calculated instantaneous electric field distribution for TE mode input in the cascaded structure.

TABLE I

Parameters of the Fabricated Bending Test Structures

\begin{tabular}{cccc}
\hline \hline Type & Radius $(\mu \mathrm{m})$ & $\begin{array}{c}\text { Offset to straight } \\
\text { waveguide }(\mathrm{nm})\end{array}$ & $\begin{array}{c}\text { Number of } 90^{\circ} \\
\text { bends }\end{array}$ \\
\hline TIR bend & 0.96 & 0 & 200 \\
\hline \multirow{4}{*}{ Arc bends } & 1.5 & 30 & 200 \\
& 2 & 20 & 200 \\
& 5 & 9 & 100 \\
\hline \hline
\end{tabular}

sufficiently small to ensure the compactness of the bends. The calculated instantaneous electric field distribution for TE mode input in the cascaded $180^{\circ}$ bend with $g=150 \mathrm{~nm}$ is shown in Fig. 5(b).

Lastly, the influence of waveguide footings to the device performance is verified. The bending loss for the proposed structure is calculated when the footing thickness is 0,20 and $30 \mathrm{~nm}$ respectively, shown as the squares in Fig. 1(b). As can be seen, due to the advantage of reflection-based bending, the influence of the thin footing is much reduced. The bending loss only increases from $0.13 \mathrm{~dB}$ to $0.24 \mathrm{~dB}$ as the footing increases from 0 to $30 \mathrm{~nm}$. On the other hand, the traditional arc bend with $1 \mu \mathrm{m}$ radius experiences much higher losses: from $0.37 \mathrm{~dB}$ to $0.95 \mathrm{~dB}$ at the same footing conditions. Therefore it is clear that the proposed sharp bend structure is more suited for complex design and processing situations, where footings are inevitable.

\section{FABRICATION AND DEMONSTRATION}

Both the proposed sharp bends and the traditional arc bends are fabricated in an InP membrane chip. The details of the processing related to this work can be found in [10] and [11]. To evaluate the loss of a single $90^{\circ}$ bend, the bends are cascaded in $\mathrm{S}$ shapes to accumulate sufficient loss for accurate measurement. The parameters of the fabricated bends are summarized in Table 1. Scanning electron microscope (SEM) pictures of the fabricated waveguide bends are shown in Fig. 6.

Fiber grating couplers are realized at the two ends of the fabricated cascades of bends for optical transmission characterization. The input and output optical fibers are placed under an angle of $9^{\circ}$ with respect to the surface normal. Commercial tunable laser and power meter modules are used as the light source and the detector. The wavelength of the tunable laser is scanned to evaluate the spectral response of the bends. Before the input fiber, a polarization controller is used to match the polarization of light to that of the grating, which

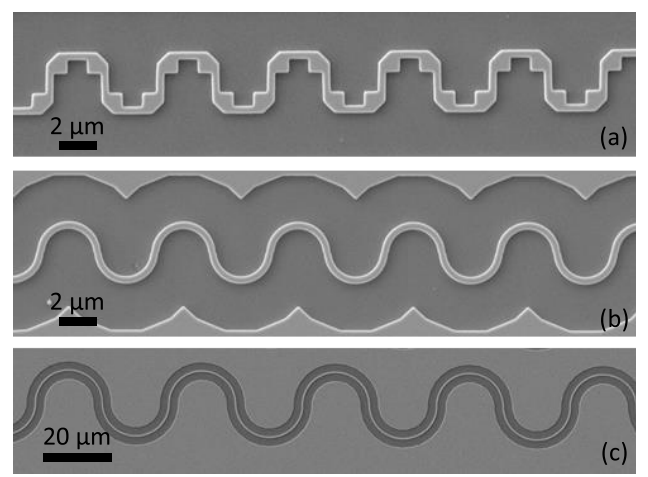

Fig. 6. (a) SEM picture of the proposed sharp bends. (b) SEM picture of the arc bends with $1.5 \mu \mathrm{m}$ radii. (c) SEM picture of the arc bends with $10 \mu \mathrm{m}$ radii.

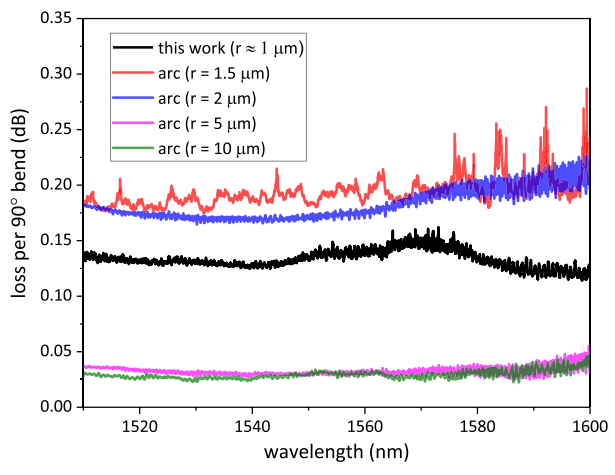

Fig. 7. Measured bending losses of the proposed structure and the reference arc bends as a function of wavelength.

is TE. Beside the cascaded bends, straight waveguides are implemented for the calibration of the loss from fiber grating couplers. Therefore the loss per $90^{\circ}$ bend can be derived by dividing the loss difference between cascaded bends and straight waveguide by the number of the bends.

The measured bending losses of the proposed sharp bend and the reference arc bends are shown in Fig. 7. As can be seen for arc bends, the loss increases significantly as the radius reduces. For relatively large radii of 5 and $10 \mu \mathrm{m}$, the loss is very low $\left(0.03 \mathrm{~dB}\right.$ per $90^{\circ}$ bend). Furthermore the bending loss for $5 \mu \mathrm{m}$ and $10 \mu \mathrm{m}$ are almost the same, indicating that for such large bending radii, the radiative loss is no longer dominant. The interaction of the optical mode with the outer sidewall of the bends is relatively weak, resulting in low bending loss. On the other hand, for relatively small bending radii (1.5 and $2 \mu \mathrm{m})$, higher losses are observed due to the stronger radiative loss as well as stronger scattering at the sidewall. Therefore the bending loss can be as high as $0.2 \mathrm{~dB}$ per $90^{\circ}$ bend. It is also worth mentioning that the offsets at arc junctions aim for loss reduction. However at the same time those abrupt discontinuities at the junctions can introduce strong reflections and scattering, especially for a very small radius with a large offset, as can be seen from the resonance-like features in the red curve $(\mathrm{r}=1.5 \mu \mathrm{m})$ in Fig. 7. The measured results of the proposed sharp bend show promising performance. The bending loss is as low as $0.13 \mathrm{~dB}$, in good agreement with the simulations, which is much lower than that for $1.5 \mu \mathrm{m}$ and $2 \mu \mathrm{m}$ arc radii, especially giving the fact that its effective radius is below $1 \mu \mathrm{m}$. The spectral 
response shows a very large operating wavelength, which is comparable to the arc bends.

\section{CONCLUSIONS}

In conclusion, we have presented a sharp waveguide bend design for membrane based optical waveguides. It has advantages such as low loss $\left(0.13 \mathrm{~dB}\right.$ per $\left.90^{\circ}\right)$, small radius $(<1 \mu \mathrm{m})$, flat wavelength response over $100 \mathrm{~nm}$, elimination of junction offsets and ease of design and fabrication. It is also advantageous over traditional arc bends for its much reduced sensitivity to waveguide footings. This structure was fabricated together with traditional arc bends. Measurement results confirmed the promising performance of this sharp bend. In the future it can be used as a basic building block for InP membrane photonic platforms.

\section{REFERENCES}

[1] J. van der Tol et al., "Photonic integration in indium-phosphide membranes on silicon (IMOS)," Proc. SPIE, vol. 8988, p. 17, 2014.

[2] D. Inoue et al., "Sub-milliampere threshold operation of butt-jointed built-in membrane DFB laser bonded on Si substrate," Opt. Exp., vol. 23, no. 6, pp. 7771-7778, Mar. 2015.
[3] D. Liang, G. Roelkens, R. Baets, and J. E. Bowers, "Hybrid integrated platforms for silicon photonics," Materials, vol. 3, no. 3, pp. 1782-1802, 2010.

[4] K. A. Williams et al., "InP photonic circuits using generic integration [Invited]," Photon. Res., vol. 3, no. 5, pp. B60-B68, 2015.

[5] D. A. B. Miller, "Device requirements for optical interconnects to silicon chips," Proc. IEEE, vol. 97, no. 7, pp. 1166-1185, Jul. 2009.

[6] Y. A. Vlasov and S. J. McNab, "Losses in single-mode silicon-on-insulator strip waveguides and bends," Opt. Exp., vol. 12, no. 8, pp. 1622-1631, Apr. 2004.

[7] W. Bogaerts and S. K. Selvaraja, "Compact single-mode silicon hybrid rib/strip waveguide with adiabatic bends," IEEE Photon. J., vol. 3, no. 3 , pp. 422-432, Jun. 2011.

[8] P. Bienstman, E. Six, M. Roelens, M. Vanwolleghem, and R. Baets, "Calculation of bending losses in dielectric waveguides using eigenmode expansion and perfectly matched layers," IEEE Photon. Technol. Lett., vol. 14, no. 2, pp. 164-166, Feb. 2002.

[9] C. Manolatou, S. G. Johnson, S. Fan, P. R. Villeneuve, H. A. Haus, and J. D. Joannopoulos, "High-density integrated optics," J. Lightw. Technol., vol. 17, no. 9, pp. 1682-1692, Sep. 1999.

[10] Y. Jiao et al., "Fullerene-assisted electron-beam lithography for pattern improvement and loss reduction in InP membrane waveguide devices," Opt. Lett., vol. 39, no. 6, pp. 1645-1648, 2014.

[11] Y. Jiao et al., "Vertical and smooth single-step reactive ion etching process for InP membrane waveguides," J. Electrochem. Soc., vol. 162, no. 8, pp. E90-E95, 2015. 